\title{
WHITE-LATINO RESIDENTIAL ATTAINMENTS AND SEGREGATION IN SIX CITIES: ASSESSING THE ROLE OF MICRO-LEVEL FACTORS
}

\author{
by
}

\author{
Amber Fox Crowell \\ California State University
}

\author{
Mark Fossett \\ Texas A\&M University
}

\begin{abstract}
CES 16-51
November, 2016

The research program of the Center for Economic Studies (CES) produces a wide range of economic analyses to improve the statistical programs of the U.S. Census Bureau. Many of these analyses take the form of CES research papers. The papers have not undergone the review accorded Census Bureau publications and no endorsement should be inferred. Any opinions and conclusions expressed herein are those of the author(s) and do not necessarily represent the views of the U.S. Census Bureau. All results have been reviewed to ensure that no confidential information is disclosed. Republication in whole or part must be cleared with the authors.

To obtain information about the series, see www.census.gov/ces or contact J. David Brown, Editor, Discussion Papers, U.S. Census Bureau, Center for Economic Studies 5K034A, 4600 Silver Hill Road, Washington, DC 20233, CES.Papers.List@census.gov. To subscribe to the series, please click here.
\end{abstract}




\begin{abstract}
This study examines the residential outcomes of Latinos in major metropolitan areas using new methods to connect micro-level analyses of residential attainments to overall patterns of segregation in the metropolitan area. Drawing on new formulations of standard measures of evenness, we conduct micro-level multivariate analyses using the restricted-use census microdata files to predict segregation-relevant neighborhood outcomes for individuals by race. We term the dependent variables segregation-relevant neighborhood outcomes because the differences in average outcomes for each group on these variables determine the values of the aggregate measures of evenness. This approach allows me to use standardization and components analysis to quantitatively assess the separate contributions that differences in social characteristics and differences in rates of return make towards determining the overall disparity in residential outcomes - that is, the level of segregation - between Whites and Latinos. Based on our microlevel residential attainment analyses we find that for Latinos, acculturation and gains in socioeconomic status are associated with greater residential contact with Whites, in agreement with spatial assimilation theory, which promotes lower segregation. However, our standardization and components analyses reveals that a substantial portion of White-Latino disparities in residential contact with Whites can be attributed to differences in rates of return; that is White-Latino differences in the ability to translate acculturation and gains in socioeconomic status into more residential contact with Whites. This is further elaborated upon by assessing the changes in contact with Whites for Whites and Latinos after manipulating single variables while holding all others constant. This can be interpreted as the role of discrimination which is emphasized by place stratification theory. Therefore we conclude that while members of minority groups make gains in residential outcomes that reduce segregation by attaining parity with Whites on social characteristics as spatial assimilation theory would predict, a substantial disparity will persist as Latinos cannot translate those gains into greater contact with Whites at the rate that Whites can. At the aggregate level of analysis, this means that White-Latino segregation remains substantial even when groups are equalized on social and economic characteristics.
\end{abstract}

\footnotetext{
${ }^{*}$ The research program of the Center for Economic Studies (CES) produces a wide range of economic analysis to improve the statistical programs of the U.S. Census Bureau. Many of these analyses take the form of CES research papers. The papers have not undergone the review accorded Census Bureau publications and no endorsement should be inferred. Any opinions and conclusions expressed herein are those of the author(s) and do not necessarily represent the views of the U.S. Census Bureau. All results have been reviewed to ensure that no confidential information is disclosed. Republication in whole or part must be cleared with the authors.
} 


\section{Introduction}

Until now research investigating residential segregation has followed one or the other of two distinct traditions. One is the tradition of micro-level studies of residential (or locational) attainment that examine how the social characteristics of individuals or households relate to neighborhood-level residential outcomes such as ethnic composition or percent in poverty. These studies provide insights about key aspects of the process of locational attainment that ultimately give rise to segregation but they have not been used to directly analyze segregation at the macro-level. The second tradition is studies of macro-level segregation that investigate the extent of uneven distribution of groups across residential areas of aggregate units such as counties, cities, and metropolitan areas. From these studies we obtain some understandings about the macro-level consequences of individual-level residential processes but have limited capacity to reveal the role that race and other social and economic characteristics play in determining the overall level of segregation for a city.

These two research traditions complement each other, each one addressing limitations of the other, to increase our sociological understanding of racial residential patterns. But to this point the field has been left with the problem that it has not been possible to draw direct quantitative connections between micro-level processes of locational attainment and macro-level patterns of residential segregation. Our study addresses and overcomes this limitation in segregation research by drawing on new methods for segregation analysis that allow us to establish how aggregate-level segregation index scores are directly determined by parameter estimates from quantitative analyses of the locational attainments of individuals and households. Specifically, we draw on new formulations of well-known segregation indices to bridge the gap between the two traditions in segregation research and quantitatively link aggregate-level 
segregation index scores to individual-level locational attainments to gain a better understanding of how micro-level social dynamics give rise to residential segregation of groups. This innovation in methods for analyzing segregation allows for us to draw conclusions about how the extent of segregation between two groups is driven not only by the impact of race and group membership but also by group differences in individual-level social and economic characteristics and by group differences in the ability to convert gains in social mobility into residential contact with Whites, two crucial aspects of residential segregation that previously have not been directly studied.

In this paper we analyze six metropolitan areas in the U.S.: Atlanta, Chicago, Houston, Los Angeles, San Diego and Seattle. These MSAs permit particular opportunities to investigate the quantitative connections between individual-level locational attainments and aggregate-level segregation index scores in detail for the White-Latino case. We conduct our analysis using the 2010 restricted-use decennial census microdata and the restricted-use 2008-2012 pooled American Community Survey microdata which, as we discuss in more detail below, allow us the unique opportunity to study the locational attainments that determine aggregate segregation at a fine level of geography. By combining new methods of analysis with the richness of the restricted-use data we thus are able to accomplish our previously stated goal of quantitatively exploring how the impact of relevant indicators of social status and acculturation such as characteristics of income, education, English language ability, nativity, and citizenship status join with the impacts of race to determine the level of White-Latino segregation for the metropolitan area.

More specifically, a goal of our paper is to demonstrate these new methods of segregation analysis and use them to clarify differences in the level and underlying nature of White-Latino 
segregation. To accomplish this we introduce new mathematical formulations of familiar segregation indices and establish how they can be understood as group differences of means in individual-level residential attainments. We then show how these segregation-determining residential outcomes can be taken as dependent variables in group-specific, multivariate locational attainment models that quantitatively assess the impact of relevant social and economic characteristics on individual-level residential outcomes. We then use the techniques of standardization and decomposition analysis to assess with greater quantitative detail and precision than ever before how aggregate segregation of Latinos from Whites traces to group differences in mean locational attainments that arise because groups differ in their means for social and economic characteristics that determine residential outcomes and also because groups differ in their ability to convert these characteristics into locational attainments.

\section{Background}

\section{Defining Residential Segregation}

There are several dimensions of segregation, but the dimension of segregation that is focused on in this study is one of the more popularly studied dimensions known as evenness. Evenness is "the degree to which the percentage of minority members within residential areas equals the citywide minority percentage; as areas depart from the ideal of evenness, segregation increases” (Massey and Denton 1989:373). Essentially, evenness refers to the distribution of a population across neighborhoods in comparison to the proportion of that group at the city level (Massey and Denton 1988). When a group is evenly distributed, every neighborhood should have the same proportion of that group as the city overall does. If the group is not evenly distributed across all neighborhoods then that implies that there are other factors at work that are causing some level of segregation (Blau 1977). The dimension of evenness has sociologically 
meaningful implications as it reflects real racial residential separation which could exacerbate issues of racial inequality on a wide range of outcomes.

\section{The Latino Population}

Our choice to focus on White-Latino segregation in this study is due to the fact that Latinos are the most dynamic population in the U.S. today, driving major demographic shifts. Characterized as being a very diverse population with a wide range of levels of segregation from Whites, we concluded that applying our methods to the complexities of White-Latino segregation would produce interesting and relevant results that could make a contribution to currently important topics in the sociological and demographic literature. Since the Immigration Act of 1965, the Latino population has grown tremendously in size due both to immigration and natural growth, having a relatively younger age structure and higher fertility rates compared to other racial-ethnic groups (Saenz 2010). Today Latinos are the largest ethnic minority group in the U.S. As of the 2010 decennial census, Latinos of all races and nationalities comprise over 16 percent of the total U.S. population, up from 12.5 percent in 2000. The largest share of this population are of Mexican origin (at 58.5 percent), who vary from being recent immigrants to people who are several generations removed from immigration or whose ancestral families resided in areas that were claimed by the U.S. after the Treaty of Guadalupe Hidalgo in 1848 which ended the Mexican-American war. The second largest group in the Latino population consists of those who are of Puerto Rican descent (9.6 percent), followed by Cubans (3.5 percent) with the remainder being of various countries in the Caribbean, Central America and South America (U.S. Census Bureau 2010).

As Saenz (2010) and others have noted, the Latino population is highly diverse due to both historical origins and immigration trends, so that today there is a vast range of language 
usage and ability, ethnic identifications, racial identifications, levels of socioeconomic status, and national origin. In general, foreign-born Latinos have lower levels of education, lower levels of income, and are less likely to speak English in comparison to native-born Latinos (Saenz 2010). This fact is especially significant because nearly 40 percent of the Latino population is foreign-born (American Community Survey 5-year Estimates 2012). The implications for Latino residential outcomes is that we may expect to see a wide dispersion of residential outcomes based on levels of socioeconomic status and social distance from non-Latino Whites. In addition, while discussions of White-Black segregation are fairly simplified by the fact that the minority population in question is of only one racial identification, Latinos are very racially diverse with some populations, such as Puerto Ricans and Dominicans, identifying as Black and finding themselves experiencing similar social outcomes as non-Latino Blacks and many other Latinos identifying as “Some other race” (Rosenbaum 1996; U.S. Census Bureau 2010).

These unique aspects of the Latino population and how they affect residential outcomes are reflected in the theoretical perspectives reviewed below, but in discussing the national level trends of Latino residential segregation, much of the focus is on how population growth, and especially the role of immigration, plays a role in the changes in Latino segregation over time (Charles 2003; Massey 2001; Massey and Denton 1987). The general finding is that Latino segregation has stayed stable or has slightly increased since 1980 on the dimension of evenness, while the residential isolation of Latinos has markedly increased during the same time frame (Charles 2003; Iceland et al. 2014; Iceland et al. 2002). Both of these trends have been attributed to population growth in one way or another, and the theoretical explanations for why this is so are based in ideas of immigrant settlement and community (Massey and Denton 1987). 
To elaborate, the general consensus in the literature is that Latinos' decreased exposure to Whites is due at least in part to changing ethnic composition in metropolitan areas. The Latino population continues to grow in traditional gateway areas such as the Southwestern region, and is growing even more rapidly in areas of the South and Midwest where Latinos are migrating to in response to labor demands (known as "new destinations"). The logical result is that Latinos have more residential contact with each other and a lessening amount of contact with Whites (Charles 2003; Iceland 2004; Iceland et al. 2014; Iceland et al. 2002; Massey 2001; Massey and Denton 1987). The explanation for why the level of uneven distribution of Latinos is remaining stable and even rising is less clear but may also be explained by population growth and patterns in initial settlement of immigrant and migrant Latinos.

In terms of where Latinos stand compared to other racial and ethnic groups in the U.S., the consistent findings in the literature show that Latinos are less segregated from Whites than Blacks are, but more segregated than Asians (Charles 2003; Iceland 2004; Iceland et al. 2002; Iceland et al. 2014; Zubrinsky and Bobo 1996). There is a nuance here, which is that when Black Latinos are observed separately, they experience levels of segregation more similar to nonLatino Blacks which demonstrates the continuing saliency of Black identity as well as the consequences of holding a double minority status (Denton and Massey 1989; Rosenbaum 1996; Scopilliti and Iceland 2008). This is reflected in the finding that Latino segregation is highest in Northeastern cities such as New York City where a larger proportion of the Latino population is of Puerto Rican or Dominican descent and racially identifies as Black. Nonetheless, while in many areas non-Latino Blacks are found to be hypersegregated, there are no observed instances of non-Black Latinos experiencing hypersegregation (Massey and Denton 1989). 
These descriptive findings about the general trends of Latino segregation, alone and in comparison to other racial and ethnic groups, provide some idea of the level of integration that Latinos experience in the U.S. This is a necessary foundation but the micro-level dynamics that produce these outcomes must be understood in order to get from merely an aggregate-level descriptive analysis to theoretically driven analyses of Latino residential outcomes and what factors influence them. Fortunately, past research in the area has already developed theoretical frameworks that prove to be useful in explaining the drivers of racial residential segregation. The two strongest and most commonly applied frameworks are spatial assimilation and place stratification. Beyond these two are several more limited theoretical perspectives that serve to explain how we may observe outcomes that deviate from the patterns predicted by spatial assimilation and place stratification.

Spatial Assimilation Theory

Spatial assimilation theory advances the hypothesis that with increased socioeconomic mobility and acculturation and over generations, members of a minority group experience residential mobility, typically defined as living in neighborhoods with a higher proportion of Whites or as dispersing to suburban areas (Alba and Logan 1991; Charles 2003; Duncan and Lieberson 1959; Massey 1985). It is further argued that residential mobility is one more step towards full integration into U.S. society, alluding to a more general process of assimilation and incorporation (Massey and Mullen 1984). The origins of this theory on assimilation and residential mobility date back to the 1920s, emerging from the Chicago School and in particular out of the work of Park and Burgess and others at the University of Chicago who conducted research on segregation and neighborhood change in Chicago during a time when immigration was driving the city's rapid growth and a significant percentage of the city's population was 
foreign-born. With rising concerns about how these immigrant groups would be able to incorporate themselves into American society, these prominent researchers of the Chicago school paid particular attention to residential patterns as a visible indicator of social separation between the different immigrant groups from each other and from the native-born.

To restate the point, the key idea of spatial assimilation is that with social mobility comes residential mobility. In general, this means that gains in socioeconomic status result in access and movement to more desirable neighborhoods and higher status groups. There has been strong support for the spatial assimilation model in the literature, especially in the case of European ethnic groups for whom immigration and nativity played a major role in shaping minority ethnic status. Contemporary research has consistently reported findings supporting the view that spatial assimilation theory has considerable relevance for explaining the residential outcomes of Latinos and Asians (Alba and Logan 1993; Charles 2003; Iceland et al. 2014; Iceland and Nelson 2008; Iceland and Scopilliti 2008; Massey 1985; Massey and Denton 1985; Yu and Myers 2007). For example, studies consistently show that, over time and across generations, Latinos can and do experience residential mobility and increased contact with Whites. However, this is an oversimplification of the story because, as has been pointed out already, Latinos are not a homogenous group with uniform outcomes but rather are racially and culturally diverse with residential patterns varying significantly across subgroups within the Latino population. In particular, past research has devoted a great deal of discussion to how immigration plays a role in the trajectory of residential outcomes for Latinos.

The definitive work of Massey (1985) discusses the concept of spatial assimilation within the context of immigration, arguing that at first immigration causes a succession process where the neighborhoods that immigrants inhabit are abandoned by native-born Whites and ethnic 
concentration emerges. Then, once immigration stops, the process of spatial assimilation accelerates and residential mobility occurs as the "social distance" between members of the ethnic groups and native-born Whites decreases. This idea is based on the observed outcomes of White European ethnic groups in the early $20^{\text {th }}$ century, but as Massey points out, “...the newest Hispanic immigrants display patterns of succession and assimilation remarkably similar to those of their predecessors” (1985: 328).

Several contemporary studies have agreed upon the idea that segregation is initially high for immigrant groups due in part to the desire to at first reside in ethnically homogenous communities where social support and ethnic-based/ethnic-serving community institutions can be found to assist in settlement and adaptation to urban life in the U.S., especially for those of lesser education and skills who are seeking out labor, or those whose household include individuals with uncertain or complicated legal status or who experience a language barrier to succeeding in the predominately English-speaking market (Clark 2002; Hall and Stringfield 2014; Iceland et al. 2014; Iceland and Nelson 2008; Iceland and Scopilliti 2008; Lichter et al. 2010; Massey 1985; Yu and Meyers 2007; Zubrinsky and Bobo 1996).

With regards to the variables that are considered in spatial assimilation models, earlier work by Massey (1985), Massey and Denton (1987), and Alba and Logan (1991; 1992; 1993) emphasize socioeconomic status and acculturation as primary factors. Socioeconomic status includes education, income, occupational prestige, and homeownership, while acculturation refers to time spent in the U.S., English language acquisition and naturalization. There is also a generational component as residential mobility operates across generations removed from immigration. The role of English language ability in the context of spatial assimilation is especially given a great deal of attention, as it can serve as a major barrier to breaking into 
certain housing markets dominated by native-born non-Latino Whites. Overall, however, studies have found positive relationships between socioeconomic gains and acculturation with residential mobility whether it is defined as suburbanization or residential contact with Whites (Alba and Logan 1991, 1992, 1993; Massey and Denton 1987; Yu and Myers 2007).

It is important to note that while Latinos and Asians have both been observed to experience a path of spatial assimilation, this framework has not been relevant for explaining residential outcomes for Blacks. Despite being predominately native-born and English-speaking, Blacks continue to be the most highly segregated minority group in the U.S. and gains in socioeconomic status do little to reduce residential separation from Whites (Massey and Denton 1987). This is where the spatial assimilation perspective approaches its limitations as it cannot account for the persistent role of race in blocking the way to residential equality, not just for nonLatino Blacks but for Latinos as well. The next theoretical framework to be discussed in this chapter, place stratification, will help address that issue.

To conclude, the final point to be made about spatial assimilation theory is that research spanning many decades has lent support for using this framework to understand Latino residential segregation, particularly Latino segregation from Whites. The relationship between social mobility and residential mobility is strong for Latinos and has been observed repeatedly. Therefore this framework will provide the primary guidance for the research design of the analyses conducted in this study. However, it is important to note that while Latinos are inarguably experiencing some level of spatial assimilation, overall segregation between Latinos and Whites is persisting over time. It might be possible to argue that this is due to a large percentage of foreign-born individuals in the Latino population, as many supporters of spatial assimilation theory have suggested, and that perhaps over time as immigration from Latin 
America continues to dwindle segregation will recede as it did for White ethnics in the early $20^{\text {th }}$ century. But there is another explanation for why segregation may continue despite Latino acculturation and gains in socioeconomic status that would otherwise predict a reduction in social distance to Whites and subsequent increase in residential contact with Whites. This is where the place stratification perspective enters into the discussion.

\section{Place Stratification}

The place stratification perspective is sometimes perceived to be a counter-theory to spatial assimilation, but in fact the two are not necessarily mutually exclusive and place stratification can also be a complementary theory that can serve to explain residential dynamics where spatial assimilation stops short (Alba and Logan 1991; Charles 2003). Place stratification essentially addresses the role of race-based discrimination in determining residential patterns and therefore is a theory of discrimination that is placed specifically within the context of how it produces racial residential segregation, with the key explanatory variable being race. The conclusions made by place stratification theory is that racial prejudices and perceptions of a racial hierarchy and advantage that the majority feels must be maintained result in Whites keeping minority group members out of their neighborhoods through housing market discrimination and avoidance of predominately non-White neighborhoods. As Logan (1978) theorized, the act of restricting minorities to certain neighborhoods in part serves to maintain an order in which the White majority group is advantaged and stands at the top.

A substantial literature exists which has explored in depth how the social mobility of minorities via gains in socioeconomic status and acculturation may not necessarily lead to integration with Whites due to race-based factors that include the discriminatory actions of the housing market and White residents as well as the reluctance on the part of minorities to live 
among Whites for fear of facing hostility. Despite major legislation being passed which outlawed race-based housing discrimination, studies to this day still find that discriminatory practices persist which block minorities from entering White neighborhoods. More insidiously, White avoidance of minority neighborhoods due to racial prejudice cannot be addressed by laws and is difficult to pinpoint, but still plays a major role in keeping neighborhoods segregated (Ellen 2000).

Support for the place stratification perspective comes from a variety of studies using both secondary data analysis as well as audit studies. Studies that have relied on secondary data have found evidence of race-based discrimination by comparing multiple groups and finding that gains in socioeconomic status and acculturation do not provide returns on residential outcomes equally across all racial and ethnic groups. While Asians and to a lesser degree non-Black Latinos experience substantial residential mobility with gains in socioeconomic status and acculturation, non-Latino Blacks and Latino Blacks do not receive the same level of returns and there is no support for an economic explanation as to why this is so, leaving the strong possibility that the U.S. history of uniquely severe racial prejudice and discrimination against Blacks is to blame (Bobo and Zubrinsky 1996; Denton and Massey 1988; Rosenbaum 1996; Zubrinsky and Bobo 1996).

Audit studies are one of the most effective ways at exploring the theory that segregation is in part due to discriminatory behaviors, particularly in the housing market (Turner 1992). For instance, Galster (1990) found that Latinos received less helpful information from agents regarding neighborhoods in comparison to Whites. Massey and Lundy (2001) found that spoken accents perceived as belonging to a Black prospective homebuyer resulted in a lower likelihood of receiving an appointment to see units in predominately White neighborhoods, a finding 
consistent with previous work by done by Purnell and colleagues (1999) who also found this to be true of people who spoke with a Chicano accent. Housing audit studies continue to reveal the role of discrimination in residential sorting and how that is changing over time, with more recent work by Turner and colleagues (2005) showing that while discriminatory practices are on the decline, they still happen at a concerning level.

To summarize, place stratification looks to the race-based factors both attitudinal and structural that can hinder minority residential contact with Whites and prevent integration. Individual attitudinal factors include unwillingness on the part of Whites to enter neighborhoods where there is a significant minority presence (Ellen 2000) and hostile reactions towards pioneering minority group members into predominately White neighborhoods (Krysan and Farley 2002; Charles 2003) . Structural factors involve discriminatory policies, public housing development in low quality neighborhoods, lending discrimination, and neighborhood steering. While discriminatory policies in real estate and lending have been outlawed, research provides evidence that there are still structural barriers to minority residence in White neighborhoods such as continuing lending discrimination and steering which are especially detrimental to nonLatino Blacks and Latinos who racially identify as Black (Denton and Massey 1989). Therefore, while spatial assimilation theory focuses on the social mobility of minority group members and their potential for residential mobility, place stratification addresses the fact that race itself still serves as a barrier to full integration due to continuing problems with discrimination and prejudiced attitudes.

For the present study, the place stratification framework will be instrumental in explaining how White-Latino segregation may still persist even after Latinos have in all important ways made social gains that would put them on comparable standing with Whites, 
including gains in income, education, English language ability, and citizenship. The fact of the matter is, while some Latinos experience only low hurdles towards integration, others are subjected to an additional and much more difficult hurdle that has been set up by ongoing racebased discrimination which is deeply rooted in the housing market and individual behaviors during neighborhood formation.

\section{Data}

The data used for analysis in this study come from two sources: the restricted-use 2010 decennial census and the restricted-use 2008-2012 American Community Survey pooled sample. The 2010 decennial census includes information on race and Latino ethnicity and is needed in order to compute block-level ethnic composition (i.e. pairwise proportion White) for calculating segregation scores. This is possible with the public-use decennial census summary files; however the need for the restricted-use files is related to the second data source. The 2008-2012 American Community Survey file is a nationally representative 5 percent sample created by pooling together annual 1 percent samples over a 5 year period. The American Community Survey collects detailed social, demographic, and economic information on individuals and households. The public-use American Community Survey microdata files, also known as the PUMS (Public Use Microdata Sample) provide access to these individual records but contain very limited geographic information in order to protect the confidentiality of the respondents. The restricted-use files, however, contain geographic information at the census block level and can be linked to the decennial census based on block IDs. For this reason, the restricted-use American Community Survey files were used in order to serve the purposes of this study, which is to link individual-level locational attainments to aggregate-level segregation patterns. Locational attainments analysis can be conducted by drawing from the American Community 
Survey for independent variables and merging in information on block-level ethnic composition from the decennial census. The decision to use the 2008-2012 pooled sample is based on two advantages. The first is that pooling 5 years of data together provides the largest possible sample for analysis. The second is that it is centered on the 2010 decennial census, making this ACS sample as time-relevant as possible.

In addition, we also use the public-use 2008-2012 American Community Survey file for descriptive statistics. Using the publicly released data for descriptive information was necessary as it is not possible to release descriptive statistics from restricted-use census data due to the confidentiality protections on the data. We are confident, however, that the estimates from the public-use files are adequately representative and reflect the composition of our analysis samples.

\section{Individual-Level Units and Variables}

The units of analysis for the locational attainment analyses are White and Latino householders, restricted to those above the age of 15 , in our six metropolitan areas of interest. Householders were identified based on their response to the relationship question on the census form. All other individuals in the household were omitted due to the fact that members of a household tend to move together, especially in the case of children. The decision to count households as a single unit based on the race of the householder as opposed to counting all individuals separately can raise some concerns due to the fact that it overlooks multiracial households. However, the occurrence of this is quite low and does not significantly affect the interpretation of the results.

The dependent variables in this study are segregation-relevant residential outcome scores that additively determine the level of segregation in the city. More specifically, these are block- 
level scores of residential outcomes with the following quality; the group difference of means on these individual level scores yields the value of the aggregate level segregation index computed using blocks. We model two kinds of residential outcomes; one that additively determines the value of the dissimilarity index and one that additively determines the separation index.

The analyses are possible because we draw on new formulations of popular segregation indices wherein the value of the index can be obtained as a difference of group means on indexspecific scores on individual-level residential outcomes (Fossett 2015). Fossett has undertaken methodological studies that establish that all popular measures of uneven distribution including, but not limited to, the dissimilarity index and the separation index that we use in the present analysis, can be formulated in a common difference of means framework where index values can be obtained from:

$$
\mathrm{S}=\mathrm{Y}_{1}-\mathrm{Y}_{2}
$$

where:

$\mathrm{S}$ is the relevant segregation score (i.e. dissimilarity or separation index)

$\mathrm{Y}_{1}$ is the mean score for Group 1 in the analysis

$\mathrm{Y}_{2}$ is the mean score for Group 2 in the analysis

The specific scoring for individual residential outcomes is dependent on which segregation score is being used. In this paper, we assess segregation using the dissimilarity index and the separation index. We next review how individual residential outcomes are scored so that it is possible to perform individual-level locational attainment analysis of residential outcomes that can be used to obtain city-level segregation index scores.

The dissimilarity index, one of the most well-known and used measures of evenness can be reformulated to follow this difference of means framework while mathematically producing 
the same result. Specifically, the dissimilarity index can be calculated by assigning values of 1 or 0 to individuals based on a comparison between the pairwise proportion White in their neighborhood (in this case, the block) and the pairwise proportion White in the city as a whole. ${ }^{1}$ If the proportion White in the individual's neighborhood is greater than or equal to the proportion White in the city as a whole, the individual receives a score of 1 . If the proportion White in the individual's neighborhood is less than the proportion White in the city as a whole, the individual receives a score of 0 . The average score for each group in the pairwise comparison (White-Latino) is then calculated and the difference in average scores is the dissimilarity index. Mathematically, this method produces the exact same score on the dissimilarity index that the conventional formulas do. The ready interpretation in this formulation is that the value of $\mathrm{D}$ indicates the White-Latino difference in percentage of the group that resides in neighborhoods where Whites are over-represented. This will be zero under even distribution and 100 when segregation is at its maximum.

The separation index (S), also known variously as the variance ratio index and eta squared, is a convenient and easily interpretable measure of evenness which has been used in many empirical studies and reviewed in many methodological studies of segregation indices (e.g., Duncan and Duncan 1955; White 1986; James and Taueber 1985; Zoloth 1976). For the separation index, the dependent variable for analysis of individual residential outcomes is a scored based on the pairwise proportion White in the block. For each individual in the analysis, the pairwise proportion White in their area of residence is assigned as their score. The particular residential outcome score assigned here has the following quality; it is possible to obtain the

\footnotetext{
${ }^{1}$ By "pairwise" we mean that only the two groups in question are included in the denominator used to calculate proportion White. The pairwise nature of the calculation is not unusual; all measures of uneven distribution are calculated using pairwise ethnic proportions. Accordingly, locational attainments that determine aggregate segregation must be calculated in a similar manner.
} 
score of the separation index for the city by taking the difference of group means on these residential outcome scores. Fossett (2015) provides derivations showing how values of the separation index obtained as a difference of means in individual residential outcomes are equivalent to the value of the separation index computed by more familiar computing formulas for the measure. These derivations also establish a simple and appealing interpretation of the separation index. For example, the value of the index indicates the White-Latino difference in (pairwise) contact with Whites. Under even distribution the difference will be zero (0); under complete segregation it will be 100 .

The resulting formulas for both segregation indices can thus be constructed like this:

(2) $\mathrm{D}=(1 / \mathrm{W}) \mathrm{W}_{\mathrm{i}} \mathrm{y}_{\mathrm{i}}-(1 / \mathrm{L}) \sum \mathrm{L}_{\mathrm{i}} \mathrm{y}_{\mathrm{i}}$

Where $y=1$ if $p \geq P$ and $y=0$ if $p<P$

(3) $\mathrm{S}=(1 / \mathrm{W}) \mathrm{W}_{\mathrm{i}} \mathrm{y}_{\mathrm{i}}-(1 / \mathrm{L}) \Sigma \mathrm{L}_{\mathrm{i}} \mathrm{y}_{\mathrm{i}}$

Where $y=p$

Where $\mathrm{W}$ is the city-level proportion White, $\mathrm{w}_{\mathrm{i}}$ is the block-level proportion White, $\mathrm{y}_{\mathrm{i}}$ is the score assigned to the individual or household, $\mathrm{L}$ is the city-level proportion Latino and $\mathrm{l}_{\mathrm{i}}$ is the block-level proportion Latino.

These formulations of the separation index and the dissimilarity index as simple differences of group means on the residential outcome of (pairwise) contact with Whites are attractive for the purposes of this study for both conceptual and practical considerations. On the conceptual side, the formulations link individual residential outcomes to aggregate-level segregation index scores in a mathematically simple and easy to understand way. On the practical side the formulations make it possible to investigate segregation by conducting individual-level analyses of segregation-relevant residential outcomes. And it also opens the 
possibilities of performing standardization and decomposition analyses based on regression analyses. That is, by running separate models for Whites and Latinos, one can assess in a quantitatively precise way how the average contact each group has with Whites is shaped by their average levels of relevant social characteristics and by their ability to translate these social characteristics into contact with Whites.

In addition, we adjust the scoring of the separation index (S) and the dissimilarity index (D) to remove a problematic upward bias that worsens as groups become disproportionate in size. This bias is a known issue in segregation measurement and is generally avoided by restricting the study of residential segregation to metropolitan areas and/or implementing a minimum population size threshold. However, a solution for removing the source of the bias exists and is described in detail in Fossett (2015, forthcoming). The adjustment is simple as it involves removing the reference individual, whether White or Latino, from the calculation of $\mathrm{p}_{\mathrm{i}}$. It is important to note that in large metropolitan areas such as those in this study, the issue of upward bias is negligible and so the unadjusted scores are similar, albeit still slightly higher.

The independent variables in the analyses capture various aspects of socioeconomic status and acculturation as well as other factors that might affect where one lives and who they live with. We review the independent variables in our models in detail below.

Socioeconomic status - To measure socioeconomic status we include educational attainment and income. Education is a six-category ordinal variable with the lowest category being those who did not attend high school and the highest being those who completed a post-graduate degree. It is treated as an interval variable in the regression analyses based on findings that the linear specification performs as well as the ANOVA style six-category specification and is centered on those who completed high school (or 
GED). Income is measured as the natural logarithm of household income bottom-coded at $\$ 500$ and is centered on the mean income of those who completed a high school education or equivalent.

Acculturation - We include several indicators of acculturation that capture the variation particularly in the Latino population. English language ability is a four-category measure ranging from no English to speaks only English or speaks English very well. This variable is centered on the category for speaking only English/speaking English very well. We also include a series of dummy variables related to citizenship by separating out those who are U.S.-born, those who are naturalized U.S.-citizens and those who are not U.S. citizens. In addition we include dummy variables for recent immigrant (within the last 15 years) and recent migrant (moved to the block within the last year).

Along with these main independent variables of interest for hypothesis testing we also control for military participation, age and family structure.

\section{Methods of Analysis}

An additional methodological innovation we adopt in this study is the use of fractional logit regression to estimate how social characteristics affect segregation-relevant residential outcomes for Whites and Latinos. The method, which draws on the generalized linear modeling (GLM) framework, was first introduced by Papke and Wooldridge (1996) in the econometrics literature and is specifically geared to modeling the mean of a bounded variable. The use of the word "logit" in the name of the method is potentially misleading as it may lead one to think that the dependent variable is a logit transformation of a proportion. In actuality, fractional logit does not transform the dependent variable in this way and instead models the mean of the dependent variable as scored in its original metric. The method involves nonlinear estimation wherein the 
curve describing the path of the mean for the dependent variable is constrained to follow a logistic "S" curve within the bounded range of the scale for the dependent variable when plotted in the original metric of the dependent variable. Coefficients are logit-style coefficients but, to reiterate, they are predicting the logit of the mean of the untransformed scores, not the mean of logit scores. The regression equations can be used to obtain predicted values either for the logit of the mean or, if desired, for the mean in the dependent variable’s original metric bounded between 0 and 1 (based on applying the inverse logit transformation to convert logit predictions of the mean to the implied mean of the proportions).

Fractional logit has attractive qualities in comparison with other methods for modeling proportions because of its ability to constrain predictions within the bounds of 0 and 1 and because it does not require special procedures for handling cases that take endpoint values. Linear regressions such as OLS do not guarantee that the predictions will remain within the bounds and are inappropriate for handling the error distribution, and other non-linear techniques such as beta regression and OLS regression of logit transformed scores must use arbitrary rescaling to deal with cases that take endpoint values of 0 and 1 (Kieschnick and McCullough 2003). Another attractive quality of implementing fractional logit regression is that it is estimated by quasi-likelihood methods which do not require that strong specific assumptions be made regarding the distribution of the error term. This is helpful when modeling a bounded dependent variable since distributions of residuals are likely to be heteroskedastic and nonnormal. Quasi-likelihood estimation is achieved using the GLM framework by specifying the option for calculating robust standard errors in combination with the logit link and binomial distribution options (Wooldridge 2002). 
We applied household analytic weights when preparing descriptive statistics and when estimating the fractional logit regression models. The American Community Survey is a 5 percent sample overall, but in some areas households are sampled at a higher rate than in other areas. Accordingly, it is necessary to use the household weights to obtain results that are representative of the population of interest. This paper presents descriptive results as well as regression results, and for this reason it is important that the sample is representative.

We draw on the location attainment regression results in several ways. To begin we review the group-specific results across cities to gain insight into White-Latino differences in the process of location attainment. We then use the results of the regression models to perform regression standardization and decomposition analysis to assess how segregation is shaped by the separate impacts of group differences in "resources" (i.e., differences in distributions on the independent variables) and group differences in "rates" (i.e., differences in the effects of the independent variables). Variations on this technique have been used at least since Kitagawa's (1955) article illustrating how standardization and decomposition analysis can be used to partition a group difference of means on an outcome into separate components reflecting the impacts of (a) group differences in distributions on relevant factors influencing the outcome ("resources”), (b) group differences in the rates of impact for these factors, and (c) the interaction or "joint impact” of differences in resources and rates. Althauser and Wigler (1972) and Jones and Kelley (1984) extended the Kitagawa method to regression-based analysis and Powers et al. (2011) extended application of these methods with nonlinear regression models such as the fractional logit model used here.

We use standardization and components analysis to answer two central questions. The first is "How does the average Latino residential outcome change when Latinos are matched with 
Whites on socioeconomic and demographic characteristics?” We answer this by performing regression standardization wherein predictions are generated for the Whites cases in the city based on coefficients from the attainment model for Latinos. This generates the hypothetical distribution of predicted values that would obtain if Latinos had the exact distribution on resources observed for Whites but converted these resources into residential attainments based on the rates observed for Latinos. The mean of these predictions can be used to assess how the average Latino residential outcome would change if Latinos were matched with Whites on resources. The second question we address is "How does the average Latino residential outcome change when Latinos are matched with Whites on rates of return?” Here we apply regression standardization once again by generating predictions for Latino cases using the coefficients from the attainment model for Whites. These predictions can be used to assess how the average Latino residential outcome would change if Latinos were able to convert resources into residential attainments at the rates of return observed for Whites.

The findings from this standardization analyses allow us to assess the separate and joint contributions that White-Latino differences in resources and White-Latino differences in rates of return make to the overall level of segregation in the city. If Whites-Latino segregation is due primarily to group differences in cultural, social, and economic characteristics (e.g., language, nativity, education, income, etc.), it will provide evidence consistent with the spatial assimilation prediction that integration with Whites will follow as Latinos acquire resources relevant for residential mobility. However, if White-Latino segregation is due primarily to group difference in the ability to convert resources into residential mobility, it will provide evidence consistent with the place stratification prediction that racial-ethnic dynamics prevent integration. 
If both factors play a non-negligible role in determining the level of White-Latino segregation, the decomposition will also provide an estimate of the "joint" impact of the resources and rates components. Quantitatively, this component reflects the fact that the estimated impact of equalizing resources will vary in magnitude depending on whether rates are as observed or have been equalized and, similarly the estimate impact of equalizing rates will vary in magnitude depending on whether resources are as observed or have been equalized. Following advice of Althauser and Wigler (1972) and Jones and Kelly (1984) we report the joint component to permit flexibility in assessing its implications across at least three scenarios. Under a scenario where Latino resources change to match Whites but racial dynamics in residential attainment continue unchanged, the joint impact component fuses with the rates component and the role of place stratification will be greater. Under a scenario where racial dynamics in residential attainment are eliminated but Latino resources continue unchanged, the joint impact component fuses with the resources component and the impact of spatial assimilation will be larger. Under a scenario where racial dynamics and Latino disadvantage in resources are both reduced simultaneously, the joint impact component should be assigned in equal part to the resource and rates components.

For linear, additive models, the components just noted can be obtained from calculations involving group means and rates. A different approach must be used in the context of nonlinear, nonadditive multivariate attainment models because the quantitative implications of changing resources and/or rates are more complicated. The approach we use is to perform standardization exercises based on predictions at the individual level to calculate the values of the resources and rates components and then obtain the value of the joint impact component by subtraction. This approach is more involved than the techniques outlined in Althauser and Wigler (1972) and 
Jones and Kelly (1984) but it has the advantage of yielding correct results both in the context of linear additive models and also in the context of nonlinear, nonadditive models. The first step in the approach is to calculate values for two observed group means and two standardized group means. The two observed group means are given as

$$
\begin{gathered}
\bar{Y}_{W_{C} W_{R}}=\text { the observed White mean (i.e., the mean of predicted values }\left(\hat{y}_{i}\right) \text { for Whites under the } \\
\text { attainment model for Whites) and } \\
\bar{Y}_{L_{C} L_{R}}=\text { the observed Latino mean (i.e., the mean of predicted values }\left(\hat{y}_{i}\right) \text { for Latinos under the } \\
\text { attainment model for Latinos). }
\end{gathered}
$$

The two standardized group means are given as

$$
\begin{aligned}
\bar{Y}_{W_{C} L_{R}}= & \text { the Latino mean standardized to Whites' characteristics (i.e., the mean of predicted values } \\
& \left(\hat{y}_{i}\right) \text { for Whites under the attainment model for Latinos) and } \\
\bar{Y}_{L_{C} W_{R}}= & \text { the Latino mean standardized to Whites' rates (i.e., the mean of predicted values }\left(\hat{y}_{i}\right) \text { for } \\
& \text { Latinos under the attainment model for Whites). }
\end{aligned}
$$

The overall level of segregation (i.e., the value of $\mathrm{D}$ ) is given by the difference between the observed means for Whites and Latinos. The value of this and the three component terms of this White-Latino difference can be obtained as follows.

(D) $\quad \bar{Y}_{W_{C} W_{R}}-\bar{Y}_{L_{C} L_{R}}=$ observed overall segregation

(D) $\quad \bar{Y}_{W_{C} L_{R}}-\bar{Y}_{L_{C} L_{R}}=$ the "characteristics" component of segregation

(D) $\quad \bar{Y}_{L_{C} W_{R}}-\bar{Y}_{L_{C} L_{R}}=$ the "rates" component of segregation

$\left(D_{J}\right) \quad D-\left(D_{C}+D_{R}\right)=$ the joint impact component of segregation.

The characteristics component of segregation $\left(D_{C}\right)$ is the difference between the expected mean under the combination of Whites' characteristics and Latinos' rates and the observed mean for Latinos. The rates component of segregation $\left(D_{R}\right)$ is the difference between the expected mean under the combination of Latinos' characteristics and Whites' rates and the observed mean for Latinos. And the joint impact component of segregation is the difference between observed overall segregation and the sum of the characteristics and rates components of segregation. To reiterate, the approach used exactly reproduces the values of parallel components obtained by 
simpler calculations that can be used in the context of linear, additive models (e.g., per Althauser and Wigler [1972] and Jones and Kelly [1984]).

We also explore the nature White-Latino segregation by conducting additional standardization exercises in which we examine predicted parity-level contact with Whites for Whites and Latinos under selected configurations on social and economic characteristics. In this we set the independent variables in the attainment models to three "profiles" of values. The first profile is of a hypothetical householder that would be disadvantaged in prospects for attaining parity contact with Whites based on having low levels of income and education, recent immigrant status, low English language ability, and no U.S. citizenship. The second profile represents a hypothetical householder that would be "typical" in prospects for attaining parity contact with Whites based on having the characteristics of a high school education, median household income, U.S. citizenship, and high English language ability. The third profile is a hypothetical householder that would be advantaged in prospects for attaining parity contact with Whites based on having a high level of education, a high household income, being U.S.-born, and having a high level of English language ability. We calculate the standardized values separately for Whites and Latinos in each city and then review them to gain insight into how White-Latino differences in predicted parity contact with Whites vary across different comparisons of social characteristics.

\section{Descriptive Results}

In Table 1 we provide descriptive statistics for samples of White and Latino householders in our six metropolitan areas based on the 2008-2012 American Community Survey PUMS (Public Use Microdata Sample) file. Our descriptive results are unsurprising, highlighting 
known inequalities between Whites and Latinos regarding education ${ }^{2}$ and income with Whites having in general a greater socioeconomic advantage. As well we also find that a higher proportion of Latinos are foreign-born and are either bilingual or do not speak English at all ${ }^{3}$, which is reflective of Latino immigration trends over the past several decades. These contrasts are sharper in more diverse metropolitan areas such as Los Angeles, Chicago, San Diego and Houston than they are in metropolitan areas like Atlanta and Seattle due to the fact that the former are far more popular and historical Latino immigrant destinations.

[Table 1 here]

In Table 2 we present further descriptive information on the level of segregation in our metropolitan areas as indicated by the dissimilarity index and the separation index. To reiterate, the dissimilarity index and the separation index are both formulated as a difference of WhiteLatino group means on neighborhood level outcomes, however they signal different aspects of racial residential distributions. As a review, D indicates the difference in the proportion of Whites who live in above parity neighborhoods (i.e. neighborhoods with a proportion White that is greater than or equal to the city-level proportion White) and Latinos who live in at or above parity neighborhoods. In contrast, while still a measure of evenness, $\mathrm{S}$ is a measure of the White-Latino difference in average neighborhood proportion White. Sometimes this can produce measures of $\mathrm{D}$ and $\mathrm{S}$ that may seem to be discordant, but this is often in situations where one group (usually the minority group) is thinly dispersed across neighborhoods and living in neighborhoods that are just below parity (especially common in cases where the minority group is disproportionately small in size) which produces high values of D while S will indicate that the two groups in question do not actually live in fundamentally different neighborhoods, producing

\footnotetext{
${ }^{2}$ Scoring on education is based on a 6-category scale ranging from 0 to 5 .

${ }^{3}$ Scoring on English language ability is based on a 4-category scale ranging from 0 to 3.
} 
a low value in $\mathrm{S}$. In Table 2, we find that $\mathrm{D}$ and $\mathrm{S}$ generally agree with each other in our cities and so our story is not complicated by these factors ${ }^{4}$.

[Table 2 here]

The components of Table 2 have straightforward interpretations. We provide the dissimilarity and separation index scores but also provide the White and Latino means on individual scoring which produce this aggregate level score. For example, in Atlanta we find that 80.75 percent of Whites live in neighborhoods at or above parity on percent White compared to 34.19 percent of Latinos. This gives us a dissimilarity index score of 46.46 from the difference of the means. The highest levels of White-Latino segregation are found in Los Angeles, followed by Chicago and Houston. All three of these metropolitan areas are known for their distinctly segregated neighborhoods and so these findings are hardly surprising. By far the lowest level of segregation is in Seattle. From this table we can emphasize that our selection of cities gives us a range of segregation levels which allow us to draw out some substantive comparisons as we continue with our analysis.

\section{Micro-Models of Locational Attainments in Six Cities}

The nature of fractional logit is such that while it directly models the mean, it still produces logit coefficients in order to fit the predictions to a logit curve thereby keeping the predictions within the logical bounds of 0 and 1 . This makes it somewhat difficult to discuss direct effects, however from these regression results we can draw several inferences about White and Latino locational attainments in our six metropolitan areas as defined by the index-specific individual outcomes that when aggregated produce the dissimilarity index and the separation index.

\footnotetext{
${ }^{4}$ We note here that D in general will always be higher than S and so for example we label D as being "low" when it is below 35 whereas we label S as "low" when it is below 20.
} 
We begin by reviewing the results based on the dissimilarity index in Table 3. Generally what we find is consistent with the spatial assimilation model, which is that most indicators of social mobility and acculturation such as income, education, English language ability and citizenship are positive predictors of residential contact with Whites which is true for both Whites and Latinos. The outcome being predicted in this model is specific to the dissimilarity index, so the positive relationships can be interpreted as indicating that Whites and Latinos with higher socioeconomic status who are U.S-born and speak English have a greater probability of living in neighborhoods where proportion White is equal to or greater than the proportion White in the metropolitan area as a whole. These outcomes are more meaningful for Latinos who are far more diverse along these characteristics and who in general have less residential contact with Whites than Whites themselves do. Referring back to Table 2, we know that Whites live in neighborhoods that on average have a much higher proportion White than Latinos. However, spatial assimilation dynamics are at work here and promote integration by increasing Latino residential contact with Whites. Latinos with higher levels of education and income, who are U.S.-born and speak English are more likely to live in neighborhoods at or above parity on percent White. This pattern is more pronounced in high segregation cities such as Los Angeles. In a later section we will elaborate on this further by generating predictions from the models which can tell us exactly how much less segregated we would expect U.S.-born Latinos with high levels of socioeconomic status to be.

[Table 3 here]

In reviewing the micro-models for the separation index in Table 4 we find matching results. Once again, all effects indicate positive relationships between social mobility and integration-promoting residential mobility. Here we interpret the results in a more direct way 
because of how the separation index is scored at the individual level in that the effects directly predict percent White in the neighborhood. Those with lower socioeconomic status who are foreign-born and do not speak English fluently live in neighborhoods with a lower percent White than the higher socioeconomic status native-born population. These locational attainment models assist us in understanding how that segregation pattern is produced at the individual level. While spatial assimilation dynamics do hold true, Latinos in general have lower socioeconomic status and are also more likely to be foreign-born in comparison to Whites and therefore high levels of segregation persist in cities where there is a larger foreign-born presence and a wider range of socioeconomic outcomes as in the case of our more highly metropolitan areas of Los Angeles, Chicago, Houston and San Diego.

[Table 4 here]

\section{Standardization on Group Resources and Rates of Return - Dissimilarity index}

In the Table 5, the standardization analysis results based on the dissimilarity index for the six case studies are presented. To review, the exercise involves generating group-specific predictions by first applying the White distributions on the independent variables to the Latino equations and then the Latino distributions on the independent variables to the White equations to see how the segregation outcome changes in each city based on these manipulations. We find changes in Latino outcomes to be dramatic in part due to the nature of the measure as discussed previously. In all cities, applying the White distributions, or "resources" to the Latino equation raises the proportion of Latinos who live in blocks at or above parity on percent White by a large amount which would imply that segregation would be much lower as a result. But the largest change happens when the Latino resources are applied to the White rates of return, suggesting that it is the disparity in the ability to convert socioeconomic gains and acculturation into 
residential mobility that contributes the most to segregation. It should again be noted that in cases such as Seattle where segregation is relatively lower, the changes are less dramatic though still large when using the dissimilarity index due to the fact that the measure can overreact to small changes based on its binary scoring related to a threshold [Table 5 here].

\section{Standardization on Group Resources and Rates of Return - Separation Index}

In this section we review the standardization results based on the separation index. Again a clear pattern emerges from this set of standardization results as Latino residential outcomes transition from being based on equations where the Latino resources and Latino rates of return are applied to equations where the White resources and White rates of return are applied. Applying the White resources raises Latino average residential contact with Whites notably in most cities. However, large changes are also seen when the White rates of return are applied in combination with the Latino resources. In every city, the effect of replacing the Latino rates of return with the White rates of return is large in magnitude except in Seattle where Latinos already have a good deal of residential contact with Whites and segregation is low. It is clear that the disparities in rates of return to social and economic characteristics play a non-negligible role in producing overall segregation patterns based on the separation index. There is a caveat here which is that it is over-simplistic to say that the differences in rates of return and in the group resources operate independently of one another, which is addressed in the components analysis in a later section of this chapter. However, the role of the difference in rates of return cannot be ignored as appears to be a large determinant of the disparities in residential outcomes between Whites and Latinos. 


\section{Components Analysis}

Components analysis is a useful tool for gaining insight into how an overall group difference in a particular outcome comes to be. In the previous section, it was evident that there were two factors that made large contributions to White-Latino differences in residential outcomes: differences in group resources based on the micro-level factors that predict segregation and differences in group rates of return on those factors. In other words, in the context of the micro-models these are the group differences in the distributions on the independent variables and the group differences in the coefficients. For each of the six case study cities, the predicted values of the dissimilarity index and the separation index are decomposed down to the contributions made by the White-Latino differences in group resources and rates of returns. There is a moderating factor which can be thought of as the joint impact of both disparities and is also included in the calculation that produces the final segregation score. We will begin by reviewing the component analysis results based on the separation index and follow with the results for the dissimilarity index. The component analysis results for each city based on the separation index are presented in Tables 7 and 8

[Table 7 here]

[Table 8 here].

The components analysis results summarize the implications of the standardization exercises presented in the previous section. In each table, the contributions made by the difference in group resources, the difference in group rates of return, and the joint impact of both are shown as summing up to the predicted segregation score for the city. We find a telling pattern in these results which is that in our highly segregated cities, the group differences in rates of return make a greater contribution to the overall segregation score, whereas in low segregation 
cities it is group composition that tends to matter more. This can be interpreted as the role of race being much greater in high-segregation cities such as Los Angeles, Chicago, Houston and San Diego as compared to lower-segregation cities like Seattle and Atlanta. With regards to the joint impact, this term can be interpreted as the moderating factor depending on which term is applied first. For instance, when Whites and Latinos in Los Angeles based on the separation index are matched on group resources, thereby reducing the score by 18.70 points, the effect of matching on rates of return is moderated by 12.41 points because the two terms do not operate independent of one another.

The finding that the largest contribution to segregation is the White-Latino differences in rates of return in high-segregation cities does not downplay the role of the White-Latino differences in resources based on social and economic characteristics. In every city where segregation is high, the role of disparities in resources which include socioeconomic status, citizenship and English language ability is not trivial, often accounting for nearly half of the overall score. With regards to the substantive implications of the findings from this exercise, we argue that there is support for spatial assimilation dynamics in that group differences in socioeconomic status and acculturation play a non-negligible rule in producing segregation, implying that with Latino gains on these factors residential mobility can occur. However we also find evidence of place stratification dynamics, or the effect of race-based barriers, in that the White-Latino differential ability to convert those gains into residential contact with Whites is at work as well, especially in high-segregation cities.

\section{Standardization on Profiles}

One final exercise that can be done using these techniques is to investigate the changes in segregation outcomes at varying levels of assimilation "profiles” where Whites and Latinos are 
first set to low scores on social and economic characteristics that would indicate low socioeconomic status and acculturation, followed by middle scores and finally high scores that would represent somebody who has high socioeconomic status and are more acculturated. The low assimilation "profile" is based on an individual set of characteristics where they have not attended high school, their household income is set to $\$ 15,000$, they have not served in the military, they are non-citizen recent immigrants, they do not speak English and they are between the ages of 15 and 29. The medium assimilation "profile" is based on the observed means on all characteristics. Finally the high assimilation "profile" is an individual with a post-graduate degree, a household income of $\$ 90,000$, they have served in the military, they are U.S.-born, they speak English exclusively or very well, and they are aged 60 or older. These profiles and their scores are presented in Tables 9 and 10

[Table 9 here]

[Table 10 here].

What we find, generally, is that segregation based on both the dissimilarity index and the separation index is highest between those in the middle "profile" on social and economic characteristics where Whites and Latinos are set at their observed means. The lowest levels of segregation alternate between when Whites and Latinos are set to the low assimilation profile and the high assimilation profile, but what we can take from this is that lower segregation occurs when Whites and Latinos are matched on characteristics as they are in the low and high assimilation profiles as compared to when they are at their group means. This is especially the case in low segregation cities where we previously found composition to matter more than rates of return such as Seattle. 


\section{Discussion}

In this paper we investigated and sought to explain the complex micro-level processes that produce White-Latino residential segregation patterns in metropolitan settings. We did so by using new formulations of the dissimilarity index and the separation index which allow us to trace segregation back to the individual-level where locational attainments are occurring and driving aggregate-level segregation patterns. We have several concluding findings from this study. First, we find that in all areas, Latinos experience greater residential contact with Whites as they acculturate and socioeconomically assimilate. Using standardization and components analysis, we find that the difference in White and Latino rates of return has a large impact on the levels of segregation, particularly in high-segregation cities. This can be interpreted as the role that race places in White-Latino segregation in high-segregation cities as compared to lowsegregation roles where differences in group composition matters as much if not more than differences in rates of return.

This study makes two significant substantive contributions to the literature. The first is that we were able to tell a more complex story about White-Latino residential segregation, both in situations where segregation is high and when it is low, by establishing the direct quantitative link between micro-level locational attainments at the block level and overall segregation in the metropolitan area. From this we were able to explain how these locational attainments give rise to and shift segregation patterns, taking research beyond the previous limitations of not being able to link segregation patterns to the micro-level social processes which produce them. The second substantive contribution is that we were able to assess the role of race even as social mobility promotes residential mobility, making it possible to work towards developing a synergy between the dominant theoretical frameworks of spatial assimilation and place stratification. 
We also have provided methodological contributions to the discipline in two ways. The first is by showcasing the usefulness of calculating segregation indices in a "difference of means” format. Mathematically the new equations produce exactly the same scores as the traditional methods, but the difference of means formulations developed by Fossett (2015) are what allow us to directly link segregation scores to individual-level outcomes thereby making the analyses in this paper possible. Secondly, we demonstrate how the complexities of residential segregation can be further explored using standardization and decomposition analysis. These methods allowed us to draw conclusions about the separate and joint impacts of social and economic characteristics and race in driving segregation patterns. We recommend both of these methodological techniques as ways to acquire a more detailed and complex understanding of residential segregation. The methods in this paper are easily applicable to the research of segregation between other groups and within other contexts, opening up opportunities to pursue larger questions about the underlying dynamics of residential segregation. 


\section{References}

Alba, Richard D. and John R. Logan. 1991. “Variations on Two Themes: Racial and Ethnic Patterns in the Attainment of Suburban Residence.” Demography 28:431-53.

Alba, Richard D. and John R. Logan. 1992. “Analyzing Locational Attainments: Constructing Individual-Level Regression Models Using Aggregate Data.” Sociological Methods \& Research 20:367-97.

Alba, Richard D. and John R. Logan. 1993. "Minority Proximity to Whites in Suburbs: An Individual-Level Analysis of Segregation.” American Journal of Sociology 98:13881427.

Alba, Richard and Victor Nee. 2003. Remaking the American Mainstream: Assimilation and Contemporary Immigration. Harvard University Press: Cambridge MA.

Althauser, Robert P. and Michael Wigler. 1972. "Standardization and Component Analysis.” Sociological Methods and Research 1:97-135.

Blalock, Hubert M., Jr. 1967. Toward a Theory of Minority-Group Relations. Capricorn Books: New York.

Blau, Peter. 1977. Inequality and Heterogeneity: A Primitive Theory of Social Structure. Free Press: New York.

Bobo, Lawrence and Camille Zubrinsky. 1996. “Attitudes on Residential Integration: Perceived Status Differences, Mere In-Group Preference, or Racial Prejudice?” Social Forces 74:883-909.

Breton, Raymond. 1964. "Institutional Completeness of Ethnic Communities and the Personal Relations of Immigrants.” American Journal of Sociology 70:193-205. 
Charles, Camille Zubrinsky. 2003. “The Dynamics of Racial Residential Segregation.” Annual Review of Sociology 29:167-207.

Clark, William A.V. 1992. "Residential Preferences and Residential Choices in a Multiethnic Context.” Demography 451-66.

Clark, William A.V. 2002. "Ethnic Preferences and Ethnic Perceptions in Multi-Ethnic Settings.” Urban Geography 23:237-56.

Denton, Nancy and Douglas Massey. 1989. "Racial Identity among Caribbean Hispanics: The Effect of Double Minority Status on Residential Segregation.” American Sociological Review 54:790-808.

Duncan, Otis Dudley and Beverly Duncan. 1955. “A Methodological Analysis of Segregation Indexes.” American Sociological Review 20:210-7.

Duncan, Otis Dudley and Stanley Lieberson. 1959. "Ethnic Segregation and Assimilation.” American Journal of Sociology 64:364-74.

Ellen, Ingrid Gould. 2000. Sharing America's Neighborhoods: The Prospects for Stable Racial Integration. Harvard University Press: Cambridge MA.

Emerson, Michael, Karen Chai and George Yancey. 2001. "Does Race Matter in Residential Segregation? Exploring the Preferences of White Americans.” American Sociological Review 66:922-35.

Farley, Reynolds, Elaine Fielding and Maria Krysan. 1997. "The Residential Preferences of Blacks and Whites: A Four-Metropolis Analysis.” Housing Policy Debate 8:763-800.

Farley, Reynolds and William Frey. 1994. "Changes in the Segregation of Whites from Blacks During the 1980s: Small Steps Towards a More Integrated Society.” American Sociological Review 59:23-45. 
Farley, Reynolds, Charlotte Steeh, Maria Krysan, Tara Jackson and Keith Reeves. 1994. "Stereotypes and Segregation: Neighborhoods in the Detroit Area." American Journal of Sociology 100:750-80.

Fischer, Mary and Marta Tienda. 2006. "Redrawing Spatial Color Lines: Hispanic Metropolitan Dispersal, Segregation, and Economic Opportunity” p. 100-37 in Hispanics and the Future of America by Marta Tienda and F. Mitchell (eds). The National Academies Press: Washington, D.C.

Fossett, Mark. 1988. "Community-Level Analysis of Racial Socioeconomic Inequality: A Cautionary Note.” Sociological Methods and Research 16:454-91.

Fossett, Mark. 2006. “Ethnic Preferences, Social Distance Dynamics, and Residential Segregation: Theoretical Explorations Using Simulation Analysis.” Journal of Mathematical Sociology 30:185-274.

Fossett, Mark. 2009. “Casting Segregation as Group Differences on Residential Outcomes.” Paper presented at the Session on Residential Segregation at the Annual Meetings of the Southern Demographic Association, Galveston, Texas, October 21-24.

Fossett, Mark. 2011. "Spatial Implementations of Mainstream Segregation Indices: Application to Assessing Segregation at Varying Scales.” Presented at the Annual Meetings of the Southwestern Sociological Association, Las Vegas, NV, March 2011.

Fossett, Mark. 2015, Forthcoming. New Methods for Measuring and Investigating Residential Segregation. Unpublished monograph under review in the Springer Series on Demographic Methods and Population Analysis. 
Fossett, Mark A. and Cynthia M. Cready. 1998. "Ecological Approaches in the Study of Racial and Ethnic Differentiation and Inequality” in Continuities in Sociological Human Ecology by Michael Micklin and Dudley L. Poston, Jr. (eds.). Plenum Press: New York.

Fossett, Mark and Amber R. Fox. 2013. "Residential Segregation and Group Differences on Social Characteristics: Limitations of Aggregate-Level Analysis and Alternative Options.” Presented at the Annual Meetings of the Southern Demographic Association, Montgomery, AL, October 2013.

Fossett, Mark, Amber R. Fox and Daniel Powers. 2014 (forthcoming). “Fractional Logit Regression and Logit Quantile Regression: New Options for Modeling Bounded Variables with an Application to Investigating Anglo-Hispanic Segregation” Sociological Methods and Research (revision of paper presented at the annual meetings of the American Sociological Association, Denver, CO.)

Fossett, Mark, Amber R. Fox, Rogelio Saenz and Wenquan Zhang. 2014. "White-Latino Residential Segregation in New Destinations: Trends for Metropolitan, Micropolitan, and Non-Micropolitan Areas, 1990-2010.” Presented at the Annual Meetings of the Population Association of America, Boston, MA, May 2014.

Fossett, Mark A. and K. Jill Kiecolt. 1989. “The Relative Size of Minority Populations and White Racial Attitudes.” Social Science Quarterly 70:820-35.

Fox, Amber R. and Mark Fossett. 2013. “Assessing the Impact of Spatial Scale in Segregation Analysis” presented at the $93^{\text {rd }}$ Annual Meetings of the Southwestern Sociological Association, New Orleans, LA, March 29 
Frey, William H. and Reynolds Farley. 1996. "Latino, Asian, and Black Segregation in U.S. Metropolitan Areas: Are Multi-Ethnic Metros Different?” Demography 33:35-50.

Galster, George. 1990. "Racial Discrimination in Housing Markets During the 1980s: A Review of the Audit Evidence.” Journal of Planning Education and Research 9:165-75. Hall, Matthew and Jonathan Stringfield. 2014. "Undocumented Migration and the Residential Segregation of Mexicans in New Destinations.” Social Science Research 47:61-78.

Harris, David. 1999. “'Property Values Drop When Blacks Move In, Because...': Racial and Socioeconomic Determinants of Neighborhood Desirability.” American Sociological Review 64:461-79.

Harris, David. 2001. “Why Are Whites and Blacks Averse to Black Neighbors?” Social Science Research 30:100-16.

Iceland, John. 2004. "Beyond Black and White: Metropolitan Residential Segregation in MultiEthnic America.” Social Science Research 33:248-71.

Iceland, John and Melissa Scopilliti. 2008. "Immigrant Residential Segregation in U.S. Metropolitan Areas, 1990-2000.” Demography 45:79-94.

Iceland, John, Daniel Weinberg and Lauren Hughes. 2014. "The Residential Segregation of Detailed Hispanic and Asian groups in the United States: 1980-2010.” Demographic Research 31:593-624.

Iceland, John, Daniel H. Weinberg, and Erika Steinmetz. 2002. Racial and Ethnic Residential Segregation in the United States: 1980-2002.” U.S. Government Printing Office, Washington, D.C. 
Iceland, John and Kyle Anne Nelson. 2008. “Hispanic Segregation in Metropolitan America: Exploring the Multiple Forms of Spatial Assimilation.” American Sociological Review 73:741-65.

Jackman, Mary. 1977. “Prejudice, Tolerance, and Attitudes toward Ethnic Groups.” Social Science Research 6:145-69.

James, David R. and Karl E. Taueber. 1985. “Measures of Segregation.” Pp. 1-32 in Sociological Methodology 1985, edited by Nancy B. Tuma. Jossey-Bass: San Francisco CA.

Jones, F.L. and Jonathan Kelley. 1984. “Decomposing Differences between Groups: A Cautionary Note on Measuring Discrimination.” Sociological Methods and Research 12:323-43.

Kieschnick, Robert and BD McCullough. 2003. "Regression Analysis of Variates Observed on (0, 1): Percentages, Proportions and Fractions.” Statistical Modeling 3:193-213.

Kitagawa, Evelyn M. 1955. “Components of a Difference Between Two Rates.” Journal of the American Statistical Association 50:1168-94.

Krysan, Maria. 2002. “Whites Who Say They’d Flee: Who Are They, and Why Would They Leave?” Demography 39:675-96.

Krysan, Maria and Reynolds Farley. 2002. “The Residential Preferences of Blacks: Do They Explain Persistent Segregation?” Social Forces 80:937-80.

Lieberson, Stanley. 1981. A Piece of the Pie: Black and White Immigrants Since 1880. University of California Press: Berkeley CA

Lichter, Daniel and Kenneth Johnson. 2009. “Immigrant Gateways and Hispanic Migration to New Destinations.” International Migration Review 43:496-518. 
Lichter, Daniel T., Domenico Parisi, Michael C. Taquino and Steven Michael Grice. 2010. “Residential Segregation in New Hispanic Destinations: Cities, Suburbs, and Rural Communities Compared.” Social Science Research 39:215-30.

Logan, John. 1978. “Growth, Politics, and the Stratification of Places.” American Journal of Sociology 84:404-16

Massey, Douglas. 1985. “Spatial Assimilation as a Socioeconomic Outcome.” American Sociological Review 50:94-106.

Massey, Douglas. 2001. “Residential Segregation and Neighborhood Conditions in U.S. Metropolitan Areas” in America Becoming: Racial Trends and Their Consequences, Volume 1 by Neil J. Smelser, William Julius Wilson, and Faith Mitchell (eds.). National Academy Press: Washington D.C.

Massey, Douglas S. and Nancy A. Denton. 1987. “Trends in the Residential Segregation of Blacks, Hispanics, and Asians: 1970-1980.” American Sociological Review 52:802-25.

Massey, Douglas S. and Nancy A. Denton. 1988. “The Dimensions of Residential Segregation.” Social Forces 67:281-315.

Massey, Douglas S. and Nancy A. Denton. 1989. "Hypersegregation in U.S. Metropolitan Areas: Black and Hispanic Segregation along Five Dimensions.” Demography 26:37391.

Massey, Douglas S. and Nancy A. Denton. 1993. American Apartheid: Segregation and the Making of the Underclass. Harvard University Press: Cambridge MA.

Massey, Douglas and Garvey Lundy. 2001. "Use of Black English and Racial Discrimination in Urban Housing Markets: New Methods and Findings.” Urban Affairs Review 36:45269. 
Massey, Douglas and Brendan Mullen. 1984. "Processes of Hispanic and Black Spatial Assimilation.” American Journal of Sociology 89:836-73.

Papke, L.E. and J.M. Wooldridge. 1996. “Econometric Methods for Fractional Response Variables with an Application to 401(k) Plan Participation Rates.” Journal of Applied Econometrics 11:619-63.

Park, Robert E. and Ernest W. Burgess. 1925. The City. The University of Chicago Press: Chicago.

Portes, Alejandro and Min Zhou. 1993. “The New Second Generation: Segmented Assimilation and Its Variants.” Annals of the American Academy of Political and Social Science 530:74-96.

Powers, Daniel A., Hirotoshi Yoshioka, and Myeong-Su Yun. 2011. “mvdcmp: Multivariate Decomposition for Nonlinear Response Models.” The Stata Journal 11:1-21.

Purnell, Thomas, William Idsardi and John Baugh. 1999. "Perceptual and Phonetic Experiments on American English Dialect Identification.” Journal of Language and Social Psychology 18:10-30.

Rosenbaum, Emily. 1996. “The Influence of Race on Hispanic Housing Choices: New York City, 1978-1987.” Urban Affairs Review 32:217-43.

Ross, Stephen and Margery Turner. 2005. "Housing Discrimination in Metropolitan America: Explaining Changes between 1989 and 2000.” Social Problems 52:152-80.

Saenz, Rogelio. 2010. “Latinos in American 2010.” Population Bulletin Update

Schill, Michael and Samantha Friedman. 1999. "The Fair Housing Amendments Act of 1988: The First Decade.” Cityscape: A Journal of Policy Development and Research 4:57-78. 
Scopilliti, Melissa and John Iceland. 2008. "Residential Patterns of Black Immigrants and Native-Born Blacks in the United States.” Social Science Quarterly 89:551-72.

Siordia, Carlos and Amber R. Fox. 2012. "Public Use Microdata Area Fragmentation: Research and Policy Implications of Polygon Discontinguity.” Spatial Demography 1:41-55.

Taueber, Karl and Alma Tauber. 1964. Negroes in Cities: Residential Segregation and Neighborhood Change. Anatheum: West Hanover PA.

Turner, Margery Austin. 1992. "Discrimination in Urban Housing Markets: Lessons from Fair Housing Audits.” Housing Policy Debate 3:185-216.

White, Michael J. 1986. "Segregation and Diversity: Measures in Population Distribution.” Population Index 52:198-221.

Wooldridge, Jeffrey M. 2002. Econometric Analysis of Cross Section and Panel Data. The MIT Press: Cambridge MA.

Yinger, John. 1998. "Evidence on Discrimination in Consumer Markets.” The Journal of Economic Perspectives 12:23-40.

Yu, Zhou and Dowell Myers. 2007. “Convergence or Divergence in Los Angeles: Three Distinctive Ethnic Patterns of Immigrant Residential Assimilation.” Social Science Research 36:254-85.

Zhou, Min. 1997. "Segmented Assimilation: Issues, Controversies, and Recent Research on the New Second Generation.” International Migration Review 31:975-1008.

Zoloth, Barbara S. 1976. "Alternative Measures of School Segregation.” Land Economics 52:278-98.

Zubrinsky, Camille and Lawrence Bobo. 1996. "Prismatic Metropolis: Race and Residential Segregation in the City of Angels.” Social Science Research 25:335-74. 


\section{Tables}

Table 1. Descriptive Statistics for White and Latino Householders

\begin{tabular}{|c|c|c|c|c|c|c|}
\hline & \multicolumn{2}{|c|}{ Atlanta } & \multicolumn{2}{|c|}{ Chicago } & \multicolumn{2}{|c|}{ Houston } \\
\hline & Whites & Latinos & Whites & Latinos & Whites & Latinos \\
\hline Education & 3.25 & 2.01 & 3.26 & 1.97 & 3.27 & 1.83 \\
\hline Median Income & $\$ 67,900$ & $\$ 36,600$ & $\$ 70,000$ & $\$ 45,000$ & $\$ 74,000$ & $\$ 40,000$ \\
\hline Military & $15.93 \%$ & $4.37 \%$ & $12.59 \%$ & $3.84 \%$ & $15.87 \%$ & $4.35 \%$ \\
\hline U.S.-born citizen & $95.58 \%$ & $27.70 \%$ & $89.64 \%$ & $40.22 \%$ & $94.22 \%$ & $39.14 \%$ \\
\hline $\begin{array}{l}\text { Foreign-Born, } \\
\text { U.S. Citizen }\end{array}$ & $2.51 \%$ & $17.21 \%$ & $7.04 \%$ & $23.77 \%$ & $2.98 \%$ & $18.50 \%$ \\
\hline $\begin{array}{l}\text { Foreign-Born, } \\
\text { Non-Citizen }\end{array}$ & $1.91 \%$ & $55.09 \%$ & $3.32 \%$ & $36.01 \%$ & $2.80 \%$ & $42.36 \%$ \\
\hline Recent Immigrant & $2.13 \%$ & $44.18 \%$ & $3.57 \%$ & $20.67 \%$ & $2.67 \%$ & $26.19 \%$ \\
\hline English Ability & 2.98 & 2.06 & 2.93 & 2.20 & 2.98 & 2.10 \\
\hline Mean Age & 50.63 & 39.46 & 52.13 & 43.24 & 51.23 & 42.29 \\
\hline $\begin{array}{l}\text { Married Couple } \\
\text { HH }\end{array}$ & $57.50 \%$ & $58.63 \%$ & $53.51 \%$ & $57.14 \%$ & $55.93 \%$ & $58.43 \%$ \\
\hline Single Mother HH & $6.62 \%$ & $12.30 \%$ & $6.71 \%$ & $14.82 \%$ & $6.68 \%$ & $14.21 \%$ \\
\hline Other Family HH & $35.88 \%$ & $29.06 \%$ & $39.78 \%$ & $28.04 \%$ & $37.39 \%$ & $27.36 \%$ \\
\hline Recent Mover & $12.32 \%$ & $20.38 \%$ & $10.20 \%$ & $13.65 \%$ & $14.31 \%$ & $18.46 \%$ \\
\hline
\end{tabular}


Table 1 (continued)

\begin{tabular}{|c|c|c|c|c|c|c|}
\hline & \multicolumn{2}{|c|}{ Los Angeles } & \multicolumn{2}{|c|}{ San Diego } & \multicolumn{2}{|c|}{ Seattle } \\
\hline & Whites & Latinos & Whites & Latinos & Whites & Latinos \\
\hline Education & 3.43 & 1.87 & 3.41 & 2.18 & 3.34 & 2.35 \\
\hline Median Income & $\$ 73,000$ & $\$ 45,000$ & $\$ 68,000$ & $\$ 44,000$ & $\$ 70,000$ & $\$ 46,200$ \\
\hline Military & $13.14 \%$ & $4.02 \%$ & $20.82 \%$ & $9.87 \%$ & $16.00 \%$ & $6.94 \%$ \\
\hline U.S.-born citizen & $83.52 \%$ & $35.04 \%$ & $91.15 \%$ & $46.14 \%$ & $92.63 \%$ & $47.15 \%$ \\
\hline $\begin{array}{l}\text { Foreign-born, } \\
\text { U.S. Citizen }\end{array}$ & $11.82 \%$ & $27.73 \%$ & $5.76 \%$ & $22.63 \%$ & $4.33 \%$ & $14.92 \%$ \\
\hline $\begin{array}{l}\text { Foreign-Born, } \\
\text { Non-Citizen }\end{array}$ & $4.66 \%$ & $37.23 \%$ & $3.09 \%$ & $31.22 \%$ & $3.04 \%$ & $37.93 \%$ \\
\hline Recent Immigrant & $4.55 \%$ & $15.20 \%$ & $2.90 \%$ & $15.36 \%$ & $3.18 \%$ & $29.64 \%$ \\
\hline English Ability & 2.91 & 2.10 & 2.96 & 2.30 & 2.97 & 2.40 \\
\hline Mean Age & 53.62 & 45.41 & 52.27 & 43.89 & 50.45 & 40.15 \\
\hline $\begin{array}{l}\text { Married Couple } \\
\text { HH }\end{array}$ & 47.11 & $53.28 \%$ & $49.94 \%$ & $54.87 \%$ & $49.83 \%$ & $48.64 \%$ \\
\hline Single Mother HH & $6.76 \%$ & $17.38 \%$ & $6.62 \%$ & $16.20 \%$ & $6.63 \%$ & $13.04 \%$ \\
\hline Other Family HH & $46.13 \%$ & $29.34 \%$ & $43.44 \%$ & $28.92 \%$ & $43.53 \%$ & $38.31 \%$ \\
\hline Recent Mover & $12.61 \%$ & $12.88 \%$ & $14.49 \%$ & $15.17 \%$ & $15.28 \%$ & $23.25 \%$ \\
\hline
\end{tabular}


Table 2. Segregation Scores

\begin{tabular}{lcc|lcc}
\hline Group & $\mathrm{D}$ & $\mathrm{S}$ & Group & $\mathrm{D}$ & $\mathrm{S}$ \\
\hline Atlanta & & & Los Angeles & & \\
Whites & 80.75 & 92.15 & Whites & 83.56 & 76.89 \\
Latinos & 33.80 & 64.12 & Latinos & 23.12 & 30.54 \\
Index Score & 46.95 & 28.03 & Index Score & 60.44 & 46.35 \\
\hline Chicago & & & San Diego & & \\
Whites & 81.29 & 88.47 & Whites & 79.61 & 81.17 \\
Latinos & 27.89 & 52.10 & Latinos & 31.46 & 49.49 \\
Index Score & 53.40 & 36.37 & Index Score & 48.15 & 31.68 \\
\hline Houston & & & Seattle & & \\
Whites & 81.22 & 77.94 & Whites & 67.99 & 93.23 \\
Latinos & 28.05 & 39.84 & Latinos & 41.22 & 83.80 \\
Index Score & 53.17 & 38.10 & Index Score & 26.77 & 9.43 \\
\hline
\end{tabular}


Table 3. Dissimilarity Index

\begin{tabular}{|c|c|c|c|c|c|c|}
\hline \multirow[b]{2}{*}{ Variable } & \multicolumn{2}{|c|}{ Atlanta } & \multicolumn{2}{|c|}{ Chicago } & \multicolumn{2}{|c|}{ Houston } \\
\hline & Whites & Latinos & Whites & Latinos & Whites & Latinos \\
\hline Degree & $0.0824 * *$ & $0.2001 * *$ & $0.2117^{* *}$ & $0.2733 * *$ & $0.2650 * *$ & $0.3715 * *$ \\
\hline Income (Ln) & $0.0482 * *$ & 0.0392 & $0.0896 * *$ & $0.0641^{* *}$ & $0.1239 * *$ & $0.0806^{* *}$ \\
\hline Military & $-0.1582 * *$ & 0.0724 & $-0.2084 * *$ & 0.0805 & $-0.2018 * *$ & 0.0707 \\
\hline U.S.-born citizen (ref) & --- & --- & --- & --- & --- & --- \\
\hline Non-U.S. citizen & $-0.2709 *$ & $-0.5292 *$ & $-0.3568 * *$ & $-0.4887 * *$ & -0.0491 & $-0.5123 * *$ \\
\hline Nat.U.S. citizen & $-0.3425 * *$ & $-0.3406 * *$ & $-0.0996 * *$ & $-0.1399 * *$ & $-0.2500 * *$ & $-0.1501^{* *}$ \\
\hline Recent immigrant & $-0.5376 * *$ & $-0.4273 * *$ & $-0.1507 * *$ & -0.0279 & -0.0355 & 0.1145 \\
\hline English ability & $0.4374 * *$ & $0.4809 * *$ & $0.2487 * *$ & $0.4429 * *$ & $0.5377^{* *}$ & $0.4191 * *$ \\
\hline Age 30-59 (ref) & --- & --- & --- & --- & --- & --- \\
\hline Age 15-29 & $-0.3952 * *$ & $-0.5287 * *$ & $-0.1958 * *$ & $-0.1952 * *$ & $-0.1354 * *$ & $-0.3024 * *$ \\
\hline Age 60+ & $0.2638 * *$ & $0.4306 * *$ & $0.3495^{* *}$ & $0.4014 * *$ & $0.1001^{* *}$ & $0.2182 * *$ \\
\hline Married couple (ref) & --- & --- & --- & --- & --- & --- \\
\hline Single mother & $-0.4482 * *$ & $-0.3107 * *$ & $-0.4767 * *$ & $-0.4415 * *$ & $-0.4805^{* *}$ & $-0.4269 * *$ \\
\hline Other family & $-0.5920 * *$ & $-0.1944 * *$ & $-0.4926 * *$ & $-0.1626 * *$ & $-0.5340 * *$ & $-0.1527 * *$ \\
\hline Recent mover & $-0.2772 * *$ & -0.1594 & 0.0002 & $0.1597 * *$ & $-0.0919 *$ & 0.0794 \\
\hline Constant & -0.3158 & $-1.9241 * *$ & $-0.6845 * *$ & $-3.0267 * *$ & $-2.0082 * *$ & $-3.2592 * *$ \\
\hline Constant (centered) & $1.6415 * *$ & $0.3090 * *$ & $1.3852 * *$ & $-0.5069 * *$ & $1.3732 * *$ & $-0.4538 * *$ \\
\hline
\end{tabular}


Table 3. Dissimilarity Index (cont'd)

\begin{tabular}{|c|c|c|c|c|c|c|}
\hline \multirow[b]{2}{*}{ Variable } & \multicolumn{2}{|c|}{ Los Angeles } & \multicolumn{2}{|c|}{ San Diego } & \multicolumn{2}{|c|}{ Seattle } \\
\hline & Whites & Latinos & Whites & Latinos & Whites & Latinos \\
\hline Degree & $0.2719 * *$ & $0.3570 * *$ & $0.2456 * *$ & $0.2178 * *$ & $0.1446 * *$ & $0.2163 * *$ \\
\hline Income (Ln) & $0.1136 * *$ & $0.0795^{* *}$ & $0.0929 * *$ & $0.0605 * *$ & $0.0772 * *$ & $0.0760 * *$ \\
\hline Military & $-0.2715^{* *}$ & -0.0177 & $-0.5731 * *$ & $0.1824 * *$ & $-0.3262 * *$ & $-0.2828 *$ \\
\hline U.S.-born citizen (ref) & --- & --- & --- & --- & --- & --- \\
\hline Non-U.S. citizen & $0.1953 * *$ & $-0.6209 * *$ & 0.1913 & $-0.6260 * *$ & 0.0407 & $-0.7396 * *$ \\
\hline Nat.U.S. citizen & $0.2794^{* *}$ & $-0.2257 * *$ & $0.3099 * *$ & $-0.5992 * *$ & 0.0250 & $-0.3132 * *$ \\
\hline Recent immigrant & -0.0746 & 0.0520 & -0.0076 & -0.0347 & $-0.3319 * *$ & -0.1957 \\
\hline English ability & 0.0054 & $0.4228 * *$ & $0.3663 * *$ & $0.4111^{* *}$ & $0.3906 * *$ & $0.3077 * *$ \\
\hline Age 30-59 (ref) & --- & --- & --- & --- & --- & --- \\
\hline Age 15-29 & $-0.1450 * *$ & $-0.4453 * *$ & $-0.3100 * *$ & -0.1258 & $-0.5320 * *$ & $-0.4349 * *$ \\
\hline Age $60+$ & $0.1908^{* *}$ & $0.3271 * *$ & $0.4611^{* *}$ & $0.3783^{* *}$ & $0.5201 * *$ & $0.4182 * *$ \\
\hline Married couple (ref) & --- & --- & --- & --- & --- & --- \\
\hline Single mother & $-0.5662 * *$ & $-0.4684 * *$ & $-0.6646^{* *}$ & $-0.6515 * *$ & $-0.6518 * *$ & $-0.3963 * *$ \\
\hline Other family & $-0.3444 * *$ & $0.0915^{* *}$ & $-0.2652 * *$ & 0.0808 & $-0.4989 * *$ & $-0.3329 * *$ \\
\hline Recent mover & 0.0231 & $0.2570 * *$ & -0.0041 & $0.1768 * *$ & $-0.2945 * *$ & $-0.2085 *$ \\
\hline Constant & $-0.3732 * *$ & $-3.6188 * *$ & $-1.3791 * *$ & $-2.6856 * *$ & $-1.4084 * *$ & $-1.8075^{* *}$ \\
\hline Constant (centered) & $1.3192 * *$ & $-0.8439 * *$ & $1.1335 * *$ & $-0.4159 * *$ & $0.8322 * *$ & $0.3157 * *$ \\
\hline
\end{tabular}


Table 4. Separation Index

\begin{tabular}{|c|c|c|c|c|c|c|}
\hline \multirow[b]{2}{*}{ Variable } & \multicolumn{2}{|c|}{ Atlanta } & \multicolumn{2}{|c|}{ Chicago } & \multicolumn{2}{|c|}{ Houston } \\
\hline & Whites & Latinos & Whites & Latinos & Whites & Latinos \\
\hline Degree & $0.0430 * *$ & $0.1605^{* *}$ & $0.1374 * *$ & $0.1733^{* *}$ & $0.1406^{* *}$ & $0.2261^{* *}$ \\
\hline Income (Ln) & $0.0372 * *$ & $0.0428 * *$ & $0.0638 * *$ & $0.0476 * *$ & $0.0661 * *$ & $0.0535 * *$ \\
\hline Military & $-0.1144 * *$ & $0.2343 *$ & $-0.1371 * *$ & $0.1247 * *$ & $-0.1096 * *$ & 0.0681 \\
\hline U.S.-born citizen (ref) & --- & --- & --- & --- & --- & --- \\
\hline Non-U.S. citizen & $-0.3130 * *$ & $-0.4008^{* *}$ & $-0.2372 * *$ & $-0.2975 * *$ & -0.0927 & $-0.2424 * *$ \\
\hline Nat.U.S. citizen & $-0.3420 * *$ & -0.1016 & $-0.0784 * *$ & $-0.1061 * *$ & $-0.1239 * *$ & -0.0360 \\
\hline Recent immigrant & $-0.1737 *$ & $-0.3353 * *$ & -0.0621 & 0.0402 & -0.0710 & -0.0151 \\
\hline English ability & $0.3365 * *$ & $0.2889 * *$ & $0.1726 * *$ & $0.2452 * *$ & $0.3226 * *$ & $0.2503 * *$ \\
\hline Age 30-59 (ref) & --- & --- & --- & --- & --- & --- \\
\hline Age 15-29 & $-0.2013 * *$ & $-0.2393 * *$ & $-0.1649 * *$ & $-0.1234 * *$ & $-0.1572 * *$ & $-0.2083^{* *}$ \\
\hline Age 60+ & $0.1737 * *$ & $0.3608 * *$ & $0.2313 * *$ & $0.1596 * *$ & $0.1315^{* *}$ & $0.0920 * *$ \\
\hline Married couple (ref) & --- & --- & --- & --- & --- & --- \\
\hline Single mother & $-0.3294 * *$ & -0.1069 & $-0.3290 * *$ & $-0.2527 * *$ & $-0.3030 * *$ & $-0.2720 * *$ \\
\hline Other family & $-0.4184^{* *}$ & $-0.2168 * *$ & $-0.3660 * *$ & $-0.1165^{* *}$ & $-0.3258 * *$ & $-0.1370 * *$ \\
\hline Recent mover & $-0.1930 * *$ & $-0.1768 * *$ & $-0.0376^{* *}$ & $0.0918 * *$ & $-0.0665 * *$ & 0.0440 \\
\hline Constant & $1.1610 * *$ & -0.1734 & $0.5723 * *$ & $-1.1008 * *$ & $-0.7101 * *$ & $-1.7442 * *$ \\
\hline Constant (centered) & $2.6270 * *$ & $1.4403^{* *}$ & $2.0060 * *$ & $0.4600 * *$ & $1.1999 * *$ & -0.0065 \\
\hline
\end{tabular}


Table 4. Separation Index (cont'd)

\begin{tabular}{|c|c|c|c|c|c|c|}
\hline \multirow[b]{2}{*}{ Variable } & \multicolumn{2}{|c|}{ Los Angeles } & \multicolumn{2}{|c|}{ San Diego } & \multicolumn{2}{|c|}{ Seattle } \\
\hline & Whites & Latinos & Whites & Latinos & Whites & Latinos \\
\hline Degree & $0.1588 * *$ & $0.2321 * *$ & $0.1292 * *$ & $0.1362 * *$ & $0.0965 * *$ & $0.1448 * *$ \\
\hline Income (Ln) & $0.0689 * *$ & $0.0533 * *$ & $0.0510 * *$ & $0.0458 * *$ & $0.0540 * *$ & $0.0349 * *$ \\
\hline Military & $-0.1564 * *$ & 0.0318 & $-.3119 * *$ & $0.1730 * *$ & $-0.2085^{* *}$ & -0.0803 \\
\hline U.S.-born citizen (ref) & --- & --- & --- & --- & --- & --- \\
\hline Non-U.S. citizen & $0.0833 * *$ & $-0.4204 * *$ & 0.0541 & $-0.3382 * *$ & -0.0208 & $-0.5486 * *$ \\
\hline Nat.U.S. citizen & $0.1860 * *$ & $-0.1809 * *$ & $0.1605^{* *}$ & $-0.3627 * *$ & 0.0051 & $-0.2987 * *$ \\
\hline Recent immigrant & $-0.0570 *$ & $0.0648 * *$ & 0.0221 & -0.0501 & $-0.2126 * *$ & $-0.1453 *$ \\
\hline English ability & $0.0329 * *$ & $0.2555^{* *}$ & $0.2137 * *$ & $0.2249 * *$ & $0.2511^{* *}$ & $0.1548 * *$ \\
\hline Age 30-59 (ref) & --- & --- & --- & --- & --- & --- \\
\hline Age 15-29 & $-0.1316^{* *}$ & $-0.3185 * *$ & $-0.2029 * *$ & $-0.0928 * *$ & $-0.2458 * *$ & $-0.1878 * *$ \\
\hline Age $60+$ & $0.1926 * *$ & $0.2071 * *$ & $0.3042 * *$ & $0.1652 * *$ & $0.2844 * *$ & $0.3113 * *$ \\
\hline Married couple (ref) & --- & --- & --- & --- & --- & --- \\
\hline Single mother & $-0.3330 * *$ & $-0.3122 * *$ & $-0.3885 * *$ & $-0.3884 * *$ & $-0.4247 * *$ & $-0.2411^{* *}$ \\
\hline Other family & $-0.2103^{* *}$ & $0.0250^{*}$ & $-0.1708 * *$ & 0.0254 & $-0.2955^{* *}$ & $-0.1802 * *$ \\
\hline Recent mover & 0.0034 & $0.1958 * *$ & -0.0150 & $0.1040 * *$ & $-0.1834 * *$ & -0.0564 \\
\hline Constant & $-0.1229 * *$ & $-2.2376 * *$ & -0.0740 & $-1.1126 * *$ & $1.1835 * *$ & $1.0965 * *$ \\
\hline Constant (centered) & $0.9801 * *$ & $-0.4753 * *$ & $1.3318 * *$ & $0.2896 * *$ & $2.6747 * *$ & $2.2027 * *$ \\
\hline
\end{tabular}


Table 5. Standardization Analysis for Dissimilarity Index

\begin{tabular}{|c|c|c|c|c|c|c|}
\hline \multirow[b]{2}{*}{ Comparison } & \multicolumn{6}{|c|}{ Predicted Group Mean on D-specific Scoring } \\
\hline & Atlanta & Chicago & Houston & Los Angeles & San Diego & Seattle \\
\hline $\begin{array}{l}\text { with Latino Group Resources } \\
\text { \& Latino Rates of Return }\end{array}$ & 33.80 & 27.89 & 28.05 & 23.12 & 31.46 & 41.22 \\
\hline $\begin{array}{l}\text { with White Group Resources } \\
\text { \& Latino Rates of Return }\end{array}$ & 62.63 & 48.21 & 52.73 & 46.98 & 52.35 & 60.65 \\
\hline $\begin{array}{l}\text { with Latino Group Resources } \\
\text { \& White Rates of Return }\end{array}$ & 59.56 & 67.35 & 60.66 & 76.17 & 68.35 & 53.42 \\
\hline $\begin{array}{l}\text { with White Group Resources } \\
\text { \& White Rates of Return }\end{array}$ & 80.75 & 81.29 & 81.22 & 83.56 & 79.61 & 67.99 \\
\hline
\end{tabular}

Table 6. Standardization Analysis for Separation Index

\begin{tabular}{|c|c|c|c|c|c|c|}
\hline \multirow[b]{2}{*}{ Comparison } & \multicolumn{6}{|c|}{ Predicted Contact with Whites } \\
\hline & Atlanta & Chicago & Houston & Los Angeles & San Diego & Seattle \\
\hline $\begin{array}{l}\text { with Latino Group Resources } \\
\text { \& Latino Rates of Return }\end{array}$ & 66.34 & 52.10 & 39.84 & 30.54 & 49.49 & 83.80 \\
\hline $\begin{array}{l}\text { with White Group Resources } \\
\text { \& Latino Rates of Return }\end{array}$ & 84.23 & 66.45 & 57.44 & 49.24 & 64.01 & 91.01 \\
\hline $\begin{array}{l}\text { with Latino Group Resources } \\
\text { \& White Rates of Return }\end{array}$ & 85.66 & 82.06 & 64.50 & 70.60 & 75.06 & 89.52 \\
\hline $\begin{array}{l}\text { with White Group Resources } \\
\text { \& White Rates of Return }\end{array}$ & 92.48 & 88.47 & 77.94 & 76.89 & 81.17 & 93.23 \\
\hline
\end{tabular}


Table 7. Components Analysis for Dissimilarity Index

\begin{tabular}{lcccccc}
\hline & \multicolumn{7}{c}{ Contribution to Index Score } \\
\hline \multicolumn{1}{c}{ Component } & Atlanta & Chicago & Houston & Los Angeles & San Diego & Seattle \\
\hline Group Resources & 28.83 & 20.32 & 24.68 & 23.86 & 20.89 & 19.43 \\
Group Rates of Return & 25.76 & 39.46 & 32.61 & 53.05 & 36.89 & 12.20 \\
Joint Impact & -7.64 & -6.38 & -4.12 & -16.47 & -9.63 & -4.86 \\
Total Difference & 46.95 & 53.40 & 53.17 & 60.44 & 48.15 & 26.77 \\
\hline
\end{tabular}

Table 8. Components Analysis for Separation Index

\begin{tabular}{|c|c|c|c|c|c|c|}
\hline \multirow[b]{2}{*}{ Component } & \multicolumn{6}{|c|}{ Contribution to Index Score } \\
\hline & Atlanta & Chicago & Houston & Los Angeles & San Diego & Seattle \\
\hline Group Resources & 18.77 & 14.35 & 17.60 & 18.70 & 14.52 & 7.21 \\
\hline Group Rates of Return & 19.85 & 29.96 & 24.66 & 40.06 & 25.57 & 5.72 \\
\hline Joint Impact & -10.59 & -7.94 & -4.16 & -12.41 & -8.41 & -3.50 \\
\hline Total Difference & 28.03 & 36.37 & 38.10 & 46.35 & 31.68 & 9.43 \\
\hline
\end{tabular}


Table 9. Dissimilarity Index at Three Levels of Assimilation

\begin{tabular}{lccc|lccc}
\hline Group & Low & Observed & High & Group & Low & Observed & High \\
\hline Atlanta & & & & Los Angeles & & & \\
Whites & 18.18 & 81.70 & 85.65 & Whites & 53.20 & 84.47 & 90.39 \\
Latinos & 3.41 & 29.73 & 78.75 & Latinos & 1.29 & 17.83 & 71.26 \\
Dissimilarity Index & 14.77 & 51.97 & 6.90 & Dissimilarity Index & 51.91 & 66.64 & 19.13 \\
\hline Chicago & & & & San Diego & & & \\
Whites & 26.83 & 82.23 & 90.75 & Whites & 21.80 & 80.53 & 86.89 \\
Latinos & 2.75 & 24.69 & 73.91 & Latinos & 2.81 & 27.57 & 74.36 \\
Dissimilarity Index & 24.08 & 57.54 & 16.84 & Dissimilarity Index & 18.99 & 52.96 & 12.53 \\
\hline Houston & & & & Seattle & & & \\
Whites & 17.98 & 82.63 & 89.57 & Whites & 10.51 & 69.05 & 78.02 \\
Latinos & 2.63 & 23.44 & 75.83 & Latinos & 5.50 & 38.94 & 72.93 \\
Dissimilarity Index & 15.35 & 59.19 & 13.74 & Dissimilarity Index & 5.01 & 30.11 & 5.09 \\
\hline
\end{tabular}


Table 10. Separation Index at Three Levels of Assimilation

\begin{tabular}{lccc|lccc}
\hline Group & Low & Observed & High & Group & Low & Observed & High \\
\hline Atlanta & & & & Los Angeles & & & \\
Whites & 62.27 & 92.22 & 93.56 & Whites & 52.52 & 77.19 & 83.14 \\
Latinos & 49.97 & 64.31 & 77.57 & Latinos & 11.47 & 28.43 & 47.72 \\
Separation Index & 12.30 & 27.91 & 15.99 & Separation Index & 41.05 & 48.76 & 35.42 \\
\hline Chicago & & & & San Diego & & & \\
Whites & 59.68 & 88.90 & 92.84 & Whites & 47.52 & 81.45 & 85.47 \\
Latinos & 31.72 & 52.71 & 66.55 & Latinos & 31.75 & 49.38 & 52.35 \\
Separation Index & 27.96 & 36.19 & 26.29 & Separation Index & 15.77 & 32.07 & 32.94 \\
\hline Houston & & & & Seattle & & & \\
Whites & 33.21 & 78.38 & 84.16 & Whites & 68.97 & 93.53 & 94.92 \\
Latinos & 19.18 & 38.96 & 56.20 & Latinos & 57.67 & 85.15 & 94.57 \\
Separation Index & 14.03 & 39.42 & 27.96 & Separation Index & 11.30 & 8.38 & 0.35 \\
\hline
\end{tabular}

